\title{
Influence of post-LASIK corneal healing on scanning laser polarimetric measurement of the retinal nerve fibre layer thickness
}

\author{
G Holló, Z Z Nagy, P Vargha, I Süveges
}

Br J Ophthalmol 2002;86:627-631

Aim: To investigate the influence of laser assisted in situ keratomileusis (LASIK) on the values for retinal nerve fibre layer thickness (RNFLT) as measured with scanning laser polarimetry (SLP) during the healing process of the cornea after LASIK.

Methods: SLP with the GDx instrument was performed on 20 consecutive healthy subjects without any eye disease undergoing LASIK for ametropia correction. The SLP measurements were performed before the surgery, and at 1 and 3 days, as well as at 3 months, after LASIK. Thickness data from images of one randomly selected eye per subject were analysed using the ANOVA and Duncan multiple comparison tests. Correlation coefficients between RNFLT data and the treatment parameters were also calculated.

Results: Somewhat similar results were found for the different retinal areas. The measured values for superior average RNFLT decreased significantly at all time points compared to the preoperative baseline $(p<0.003$, Duncan test), but increased significantly between postoperative day 1 and the final visit at 3 months $(p=0.025$, Duncan test). Inferior average RNFLT in the early postoperative days was significantly smaller than at 3 months after LASIK $(p<0.05$, Duncan test), and tended to be smaller than at baseline. The thickness values before surgery and at the final visit, however, showed no significant difference $(p=0.698$, Duncan test) in this region. Ellipse average RNFLT was significantly smaller in the early postoperative days than the baseline value before LASIK. However, the measured value had significantly increased again by the time of the final visit ( $p<0.02$, Duncan test). This value at the final visit showed no difference from the baseline value $(p=0.46$, Duncan test). The changes in the nasal average and temporal average RNFLT were not statistically significant. No correlation was found between the change in the SLP measured thickness values and central corneal thickness at baseline and its change after surgery, nor with the change in cylindrical correction due to LASIK, or the length of the suction time during surgery $(p>0.05$ for all correlations).

Conclusion: The SLP technique is sensitive to the corneal optical properties, and RNFLT as measured with SLP shows changes after LASIK. Most of these changes, however, diminish with time after surgery, and the values tend to return to the preoperative results during the first 3 months of corneal healing following uncomplicated LASIK. It appears that in uncomplicated cases the transient RNFLT changes are artefacts and do not imply pathological thickness alterations due to LASIK.
S canning laser polarimetry (SLP) of the retinal nerve fibre layer has become a widely used technique for glaucoma diagnosis $^{1-7}$ and, more recently, for follow up monitoring. ${ }^{8-10}$ The measurement principle is based on the optical retardation caused by the parallel retinal nerve fibres around the optic nerve head in the illuminating laser beam, which is reflected from the eye back to the detector. ${ }^{11}$ The linear relation between the thickness of the retinal nerve fibre layer and the measured optical retardation ${ }^{11}$ is used for the software provided calculation of the retinal nerve fibre layer thickness (RNFLT) in each pixel of the image. These measurements provide the basis for the calculation of the RNFLT for the different retinal sectors, and for the diagnostic algorithm for the detection of glaucoma. Since glaucoma is defined as a progressive loss of the retinal ganglion cells and their axons, ${ }^{12}{ }^{13}$ SLP provides a non-invasive technique which is, in principle, specific for the diagnosis and follow up of glaucoma and other optic neuropathies.

Optical retardation, however, is caused not only by the axons of the retinal ganglion cells. The cornea is another important source of retardation, and this fact influences the diagnostic sensitivity of SLP. ${ }^{15}$ The commercially available instrument for SLP, the GDx nerve fibre analyser (Laser Diagnostic Technologies, Inc, San Diego, CA, USA, Software Version 1.0.16) contains a built-in compensator, which compensates for the average corneal polarisation axis; but it cannot be individualised for the particular eye. Since the axis of corneal polarisation has been found to be stable over a period of at least 1 year, ${ }^{16}$ this would not seem to affect the longitudinal follow up with SLP, provided that the cornea remains intact. However, refractive corneal surgery, such as photorefractive keratectomy and laser in situ keratomileusis (LASIK), does influence the status of the cornea. Since tonometry after LASIK and photorefractive keratectomy underestimates the true intraocular pressure due to the decrease of the central cornea thickness, ${ }^{17-21}$ SLP will in future probably attain even greater importance in glaucoma diagnosis and follow up after refractive corneal surgery. It has been demonstrated by our group, ${ }^{22}$ and confirmed by other authors ${ }^{23}$ that SLP measurements and the reproducibility of the SLP measurement are not influenced by photorefractive keratectomy. In contrast with this a decrease of polarimetric RNFLT has been reported in the early period following LASIK surgery. ${ }^{24-26}$ However, at the same time the RNFLT as measured with scanning laser tomography and optical coherence tomography remained stable. ${ }^{26}$ This

Abbreviations: BSCVA, best spectacle corrected visual acuity; BSS balanced salt solution; LASIK, laser assisted in situ keratomileusis; RNFLT, retinal nerve fibre layer thickness; SLP, scanning laser polarimetry; UCVA, uncorrected visual acuity 
Table 1 Statistics of the parameters tested for correlation with the polarimetric RNFLT changes

\begin{tabular}{lll}
\hline & Mean (SD) & Range \\
\hline Central corneal thickness at baseline $(\mu \mathrm{m}), \mathrm{n}=20$ & $563.55(35.38)$ & $510-635$ \\
Decrease of central corneal thickness due to LASIK ( $\mu \mathrm{m}), \mathrm{n}=20$ & $83.45(22.94)$ & $27-119$ \\
Decrease of cylindrical refractive error due to LASIK (D), $\mathrm{n}=12$ & $1.36(1.48)$ & $0.5-4.5$ \\
Duration of suction during LASIK (second), $\mathrm{n}=20$ & $46.90(10.38)$ & $30.0-79.0$ \\
\hline
\end{tabular}

suggests that the polarimetric alterations in uncomplicated cases are probably artefacts caused by alterations of the corneal polarisation. In a few case reports, ${ }^{27-29}$ however, the development of true visual field defects and optic neuropathy have been reported as a consequence of the $60-80 \mathrm{~mm} \mathrm{Hg}$ suction applied to the eye during the LASIK procedure. This suggests that any reduction of the polarimetric RNFLT after LASIK should be evaluated individually for each patient.

Despite the LASIK induced alterations, SLP remains an important technique for the diagnosis and follow up of glaucoma after LASIK treatment, therefore it is of practical importance to evaluate the stability of the polarimetric RNFLT alterations following LASIK. In order to investigate this problem, in the present study SLP measurements were performed repeatedly between the day before surgery and the 3 months after LASIK, to follow the alterations in the measured values during the healing process of the cornea.

\section{PATIENTS AND METHODS}

The clinical investigation protocol was approved by the ethics committee of the university. Twenty consecutive healthy white subjects (age 33.6 (SD 9.9) years) without any ocular disease and abnormality except for ametropia were enrolled in the study in January 2001. Written informed consent was obtained from each participant. The patients had no history of eye disease. Uncorrected visual acuity (UCVA) and best spectacle corrected visual acuity (BSCVA) were assessed in the preoperative period. Slit lamp examination, Goldmann applanation tonometry, funduscopy, automated refractometry with and without pupil dilatation and cycloplegia, corneal topography (TMS-III topograph, Tomey Inc, New York, NY, USA) and ultrasonic pachymetry (Model 850 pachymeter, Humphrey Inc, San Leandro, CA, USA) were also performed before the LASIK. All eyes were evaluated as being normal. The central corneal thickness was greater than $500 \mu \mathrm{m}$ in each eye. Intraocular pressure in each eye was consistently below 22 $\mathrm{mm} \mathrm{Hg}$, and the optic nerve heads showed no pathological alterations as examined using a 90 dioptre non-contact aspherical lens and a slit lamp for stereoscopic viewing. In the myopic eyes with more than $-8.0 \mathrm{D}$ of preoperative refractive error, axial length measurement using the ultrasound A-scan method was performed. Patients were asked not to wear their contact lenses for at least 3 weeks before the preoperative assessment.

Preoperative spherical refractive error of the eyes involved in the analysis varied between $-12.0 \mathrm{D}$ and $+7.5 \mathrm{D}$; the mean (SD) was -4.45 (5.96) D. Five eyes were hyperopic and 15 eyes were myopic before surgery. The preoperative cylindrical refractive error (found in 12 of the 20 eyes) varied between $-5.0 \mathrm{D}$ and $+0.5 \mathrm{D}(-1.50(1.74) \mathrm{D})$. The statistics of the corneal and LASIK parameters used for the correlation with the polarimetric RNFLT changes are shown in Table 1.

The LASIK procedure was started using the Moria CB microkeratome (Carriazzo-Barraquer, Moria SA, Antony, France). A $130 \mu \mathrm{m}$ flap thickness was used, and the flap hinge was positioned at the $12 \mathrm{o}^{\prime}$ clock position. A $9.0 \mathrm{~mm}$ flap diameter was used for eyes with myopic and myopic astigmatic refractive error, whereas in eyes with hyperopia a $9.5 \mathrm{~mm}$ flap diameter was chosen. The eye was fixed with a suction ring using $60 \mathrm{~mm} \mathrm{Hg}$ negative pressure; this pressure was built up gradually. The statistics for the duration of the suction are shown in Table 1. The average time of flap creation was $3 \mathrm{sec}-$ onds. Following the flap preparation the suction ring was gradually disengaged. The flap was gently lifted with a spatula and a $13.0 \mathrm{~mm}$ metal ring was placed on the surface of the eye without any suction; this served as a contrasting marker object for the eye tracker of the excimer laser. Refractive treatments were carried out with an Asclepion Meditec MEL $70_{\text {G-scan }}$ flying spot excimer laser (Asclepion-Meditec AG, Jena, Germany). The laser operated with a $250 \mathrm{~mJ} / \mathrm{cm}^{2}$ fluence, with a $1.9 \mathrm{~mm}$ beam diameter and $38 \mathrm{~Hz}$ repetition frequency. ${ }^{30}$ The treatment diameter was $6 \mathrm{~mm}$ on the central cornea in myopic and myopic astigmatic eyes. In hyperopic eyes the treatment diameter was $6 \mathrm{~mm}$ with a $3 \mathrm{~mm}$ transition zone. Following refractive treatment the flap was repositioned, and balanced salt solution (BSS) was used to irrigate under the flap. A pause of 5 minutes was allowed for complete flap adhesion. Patients received topical ciprofloxacin and fluorometholone four times daily for 1 week. During the follow up period of the present study visual acuity (UCVA and BSCVA) was measured on the first and fifth postoperative days, as well as at 1 month and 3 months after surgery. Corneal ultrasonic pachymetry was performed between 1 and 3 months postoperatively.

SLP of the retinal nerve fibre layer was performed without pupil dilatation using the GDx nerve fibre analyser. This noninvasive measurement technique has been described in detail in elsewhere. ${ }^{1-10}$ In brief, a beam of $780 \mathrm{~nm}$ polarised laser light is projected onto the retina by the instrument. The birefringent, parallel nerve fibres cause retardation in the polarisation of the light passing trough them, compared to the light passing between the fibres. This retardation of the reflected light is measured automatically by the detector unit of the instrument. The degree of the retardation corresponds to the thickness of the RNFL, and is analysed by the built-in polarisation detection unit. RNFL thickness is automatically calculated and imaged in a colour coded manner in each of the $256 \times 256$ individual retinal positions (pixels) of a $15^{\circ}$ retinal area. To stabilise fixation an external fixating light is used. The optic nerve head is positioned in the centre of the display. Image acquisition requires only 0.7 seconds.

In our investigations, three high quality individual images were acquired in each case, and an averaged baseline image was calculated from them using the software. The baseline images calculated on the various different occasions were used for the evaluation of RNFLT changes with time. The contour of the optic nerve head was defined by the operator. The 10 pixels wide measuring ellipse was set 1.75 disc diameter from the centre of the optic nerve head. Default quadrant positions and blood vessel removal algorithm were used. Parameters showing RNFLT in the central part of the image (superior, inferior, temporal and nasal average thickness values, and ellipse average thickness) as well as average RNFLT calculated from the total image area (average thickness) were used for the analysis. The definition of each polarimetric parameter is shown in Table 2. Nerve fibre analysis was performed before the LASIK procedure and on the first and third postoperative days, as well as at a follow up visit 3 months after surgery. 


\begin{tabular}{ll}
$\begin{array}{l}\text { Table } 2 \text { Definition of the retinal thickness parameters } \\
\text { analysed in this study }\end{array}$ & \\
\hline RNFLT parameter & Definition \\
\hline Superior average thickness & $\begin{array}{l}\text { Average thickness }(\mu \mathrm{m}) \text { for the } \\
\text { pixels in the superior quadrant of } \\
\text { the measuring ellipse }\end{array}$ \\
Inferior average thickness & $\begin{array}{l}\text { Average thickness }(\mu \mathrm{m}) \text { for the } \\
\text { pixels in the inferior quadrant of } \\
\text { the measuring ellipse }\end{array}$ \\
Temporal average thickness & $\begin{array}{l}\text { Average thickness }(\mu \mathrm{m}) \text { for the } \\
\text { pixels in the temporal quadrant of } \\
\text { the measuring ellipse } \\
\text { Average thickness }(\mu \mathrm{m}) \text { for the } \\
\text { pixels in the nasal quadrant of the } \\
\text { measuring ellipse } \\
\text { Average thickness }(\mu \mathrm{m}) \text { for the } \\
\text { pixels along the total measuring } \\
\text { ellipse } \\
\text { Average thickness }(\mu \mathrm{m}) \text { for all } \\
\text { usable pixels in the total image } \\
\text { area }\end{array}$ \\
\hline
\end{tabular}

The LASIK procedure and all the connected examinations were performed by one of us (ZZN) with experience in corneal refractive surgery. The SLP examinations were performed in a masked fashion by another examiner $(\mathrm{GH})$ with experience in RNFLT measurement. SLP image analysis and the calculations were performed after the end of the 3 month follow up period, but before unmasking the data on refraction and the details of the LASIK procedure. One randomly selected eye per participant was included in the evaluation.

ANOVA for repeated measurements was used to compare the RNFLT values between the different time points. If the alteration evaluated with ANOVA was significant, the Duncan test was used for paired comparison. Correlation coefficients were calculated to investigate the association between the change in the SLP parameters and the central corneal thickness, its alteration due to LASIK, the change in the cylindrical correction for BSCVA, and the duration of suction during surgery. p Values of less than 0.05 were considered statistically significant.

\section{RESULTS}

The LASIK procedure and the postoperative period were uncomplicated in all eyes. It was possible to perform SLP in each case at all time points; however, the illumination intensity necessary to obtain a high quality image showed considerable variation during the follow up period. At baseline the minimum intensity was sufficient for the acquisition of an optimal image, which is typical for healthy eyes without media opacities in young subjects. At 1 day and 3 days after LASIK, however, the intensity had to be increased to the maximum available in order to obtain images of similar good quality. At the final visit, the intensity setting necessary for optimal imaging was again low, and very similar to that needed before surgery.

The changes of the measured RNFLT values are shown in Table 3. Superior average thickness decreased significantly at all time points compared to baseline, but increased significantly between day 1 and the final visit $(p=0.025$, Duncan test). Inferior average thickness in the early postoperative days was significantly smaller than at the final visit (Duncan test, $\mathrm{p}<0.05)$, and tended to be smaller than at baseline. There was no difference between the baseline and the final inferior average thickness values $(p=0.698$, Duncan test). Ellipse average RNFLT was significantly smaller in the early postoperative days than either before or 3 months after the LASIK procedure $(p<0.02$, Duncan test). No difference was seen in ellipse average thickness between the baseline and the final value $(\mathrm{p}=0.46$, Duncan test $)$. The alteration in the temporal and nasal average RNFLT was not statistically significant. Average

Table 3 RNFLT values at baseline, and their changes during the healing process of the cornea after LASIK. The definitions of the thickness parameters are shown in Table 2

\begin{tabular}{|c|c|c|c|c|c|c|c|c|c|}
\hline \multirow[b]{2}{*}{ SLP parameter $(\mu \mathrm{m})$} & \multicolumn{2}{|l|}{ Baseline (1) } & \multicolumn{2}{|l|}{ Day 1 (2) } & \multicolumn{2}{|l|}{ Day 3 (3) } & \multicolumn{2}{|l|}{ Month 3 (4) } & \multirow[b]{2}{*}{$\mathrm{p}$ Value } \\
\hline & Mean (SD) & $95 \% \mathrm{Cl}$ & Mean (SD) & $95 \% \mathrm{Cl}$ & Mean (SD) & $95 \% \mathrm{Cl}$ & Mean (SD) & $95 \% \mathrm{Cl}$ & \\
\hline Superior average thickness & 79.6 (16.5) & $\begin{array}{l}71.9 \text { to } \\
87.4\end{array}$ & 71.6 (11.2) & $\begin{array}{l}66.2 \text { to } \\
77.0\end{array}$ & $72.6(12.1)$ & $\begin{array}{l}66.9 \text { to } \\
78.3\end{array}$ & 74.4 (12.3) & $\begin{array}{l}68.6 \text { to } \\
80.2\end{array}$ & $\begin{array}{l}\mathrm{pt}_{1-2}=0.0005 \\
\mathrm{pt}_{1-3}=0.001 \\
\mathrm{pt}_{1-4}=0.002 \\
\mathrm{pt}_{-2-3}=0.220 \\
\mathrm{pt}^{-4-4}=0.025 \\
\mathrm{pt}_{3-4}=0.246\end{array}$ \\
\hline Inferior average thickness & $80.7(17.8)$ & $\begin{array}{l}72.4 \text { to } \\
89.0\end{array}$ & $77.6(11.0)$ & $\begin{array}{l}72.3 \text { to } \\
82.9\end{array}$ & $77.1(12.3)$ & $\begin{array}{l}71.4 \text { to } \\
82.9\end{array}$ & $81.1(13.6)$ & $\begin{array}{l}74.7 \text { to } \\
87.4\end{array}$ & $\begin{array}{l}\mathrm{pt}_{1-2}=0.083 \\
\mathrm{pt}_{-1-3}=0.076 \\
\mathrm{pt}_{1-4}=0.698 \\
\mathrm{pt}_{2-3}=0.956 \\
\mathrm{pt}_{2-4}=0.042 \\
\mathrm{pt}_{3-4}=0.041\end{array}$ \\
\hline Temporal average thickness & $53.7(22.7)$ & $\begin{array}{l}43.0 \text { to } \\
64.3\end{array}$ & $52.7(19.5)$ & $\begin{array}{l}43.3 \text { to } \\
62.1\end{array}$ & $52.1(20.4)$ & $\begin{array}{l}42.5 \text { to } \\
61.6\end{array}$ & $56.5(22.0)$ & $\begin{array}{l}46.2 \text { to } \\
66.8\end{array}$ & $p^{*}=0.119$ \\
\hline Nasal average thickness & $57.6(13.1)$ & $\begin{array}{l}51.5 \text { to } \\
63.7\end{array}$ & $55.7(9.5)$ & $\begin{array}{l}51.1 \text { to } \\
60.3\end{array}$ & $54.8(10.5)$ & $\begin{array}{l}49.9 \text { to } \\
59.8\end{array}$ & 57.6 (13.2) & $\begin{array}{l}51.4 \text { to } \\
63.8\end{array}$ & $p^{*}=0.134$ \\
\hline Ellipse average thickness & $72.1(14.0)$ & $\begin{array}{l}65.6 \text { to } \\
78.7\end{array}$ & $68.2(9.0)$ & $\begin{array}{l}63.8 \text { to } \\
72.5\end{array}$ & $67.8(10.3)$ & $\begin{array}{l}63.0 \text { to } \\
72.7\end{array}$ & $71.0(11.3)$ & $\begin{array}{l}65.7 \text { to } \\
76.3\end{array}$ & $\begin{array}{l}\mathrm{p}_{1-2}=0.002 \\
\mathrm{pt}_{1-3}=0.004 \\
\mathrm{pt}_{1-4}=0.463 \\
\mathrm{pt}_{2-3}=0.816 \\
\mathrm{pt}^{-4-4}=0.014 \\
\mathrm{pt}_{3-4}=0.019\end{array}$ \\
\hline Average thickness & $66.2(12.8)$ & $\begin{array}{l}60.2 \text { to } \\
72.2\end{array}$ & $62.9(8.9)$ & $\begin{array}{l}58.6 \text { to } \\
67.2\end{array}$ & $62.8(9.7)$ & $\begin{array}{l}58.2 \text { to } \\
67.4\end{array}$ & $63.9(10.3)$ & $\begin{array}{l}59.1 \text { to } \\
68.7\end{array}$ & $\begin{array}{l}\mathrm{pt}_{1-2}=0.002 \\
\mathrm{pt}_{1-3}=0.004 \\
\mathrm{pt}_{1-4}=0.046 \\
\mathrm{pt}_{2-3}=0.698 \\
\mathrm{pt}_{2-4}=0.174 \\
\mathrm{pt}_{3-4}=0.289\end{array}$ \\
\hline
\end{tabular}

$\mathrm{p}^{*}=$ ANOVA for repeated measurements;

$\mathrm{p} \dagger=$ Duncan test 
thickness over the whole image area decreased significantly after LASIK ( $p<0.05$, Duncan test).

No correlation was found between the change of any SLP parameters investigated and the parameters shown in Table 2-that is, the central corneal thickness at baseline and its change after surgery, the decrease of the cylindrical correction due to LASIK, and the length of the suction time during surgery ( $p>0.05$ in all cases, detailed data not shown).

\section{DISCUSSION}

In the present study the LASIK induced change of the polarimetric RNFLT measurements, and the stability of this alteration during the healing process of the cornea, were investigated in healthy but ametropic eyes. The background of this investigation is that RNFLT as measured with SLP using the GDx nerve fibre analyser was found to be reduced following uncomplicated LASIK procedure, which seems to be caused by the corneal alterations induced by the refractive treatment. ${ }^{24-26}$ In contrast with photorefractive keratectomy, which has been shown not to influence polarimetric measurements of the RNFLT, ${ }^{22}$ a significant difference in the LASIK procedure is that a $60-80 \mathrm{~mm} \mathrm{Hg}$ suction is applied to the eye in order to stabilise it during the surgery. This suction has been reported to cause true ganglion cell damage resulting in visual field defects in some cases, ${ }^{27-29}$ which suggests that the RNFLT decrease after LASIK should be carefully evaluated for each individual patient. Nevertheless, despite the disturbing influence of LASIK SLP will in future probably have a special practical importance in the diagnosis and follow up of glaucoma in patients who have been treated with LASIK, since tonometry is irreversibly influenced by the thinning of the central cornea achieved in refractive surgery. This results in false low intraocular pressure readings ${ }^{17-21}$ not suitable for glaucoma diagnosis or follow up. But in order to be able to use SLP for these purposes, it is essential to investigate the question of the stability of the polarimetric RNFLT measurements after LASIK.

In previous studies ${ }^{24-26}$ investigators have compared the corresponding SLP values before and after LASIK surgery, but the potential influence of the healing process of the cornea on the SLP measurements was not investigated. The postoperative SLP values were collected at different time periods, between 1 week and 2 months after surgery. ${ }^{24-26}$ In uncomplicated cases any change in the polarimetric RNFLT is attributed to the altered birefringence of the laser treated cornea, and it is known that the status of the cornea is different in the early period after LASIK compared to some months later. ${ }^{31-34}$ Therefore, in this study we investigated whether the healing process of the cornea after LASIK has any influence on the SLP measurements, or whether an SLP measurement performed in the early postoperative period after LASIK can be considered stable and a potential baseline for any long term follow up evaluations.

The SLP parameters investigated in the present study were exclusively the direct thickness parameters. The calculated parameters and ratios derived by the software were excluded from the analysis, in order to allow a clearer appreciation of the results. The thickness parameters investigated can be divided into two groups; the parameters representing the centre of the polarimetric image (superior, inferior, temporal, nasal, and ellipse average thickness), and the parameter which is calculated from all pixels of the total image area, including information also from the peripheral parts of the image (Table 2 ). The significance of the distinction between the two kinds of parameters is that the central part of the polarimetric image is imaged via the laser treated central corneal area, while the information from the more peripheral parts of the retina might be influenced also by additional factors originating from the paracentral cornea, which represents a transition between the treated and untreated areas.
In this study we found that all thickness values from the centre of the image, except for the temporal and nasal RNFLT, decreased significantly or tended to decrease after LASIK on the first and third days after surgery (Table 3), but either returned to baseline (inferior average thickness and ellipse average thickness) or tended to return to baseline (superior average thickness) by the time of the last visit, at 3 months after surgery. Since the refractive surgery and the postoperative period were uncomplicated, and we found no correlation between the duration of the suction during surgery and the change in the RNFLT, the polarimetric alterations were considered a consequence of the alteration of the corneal birefringence due to LASIK. The fluctuation clearly shows that the decrease of measured RNFLT was not caused by retinal ganglion cell loss, since the thickness increased during the follow up time after surgery. Though the exact reasons for the initial decrease of the polarimetric RNFLT and its subsequent fluctuation remain unknown, one may suppose that the transient stromal corneal oedema and the temporary disturbance of the corneal surface, ${ }^{31} 32$ microfolds in the Bowman's layer and in the anterior stroma, ${ }^{33}{ }^{34}$ and especially the occurrence of particles in the flap interface area (which when viewed with in vivo confocal corneal microscopy are highly reflective) ${ }^{33} 34$ are major factors in this "virtual" thinning of the nerve fibre layer. This idea is strongly supported by our observation regarding the required intensity of the illuminating laser light. Before LASIK the intensity required for optimal imaging was sufficient at its minimum setting. On the first and third days after surgery it had to be increased to its maximum value; but at the end of the study the optimal intensity was similar to the baseline level. The time profile of the required illumination intensity is similar to the time profile of the density of the particles observed with in vivo confocal corneal microscopy in the flap interface area of the central cornea after LASIK. ${ }^{34}$ The density of these reflective particles is high in the early postoperative days, and decreases significantly during the early months after LASIK to reach a stable level at 3 months after surgery. ${ }^{34}$ The particles, which are hypothesised to be microscopic metallic debris from the surgery, cellular debris, or inflammatory cells, ${ }^{33}{ }^{34}$ might have significantly increased the corneal reflection of polarised laser light during the SLP measurements. This would then mean that an increased light sensitivity was needed in order to achieve a sufficient illumination of the retina, as was observed in fact.

The alteration of the GDx "average thickness" parameter, which represents the average of all thickness values available in the image, showed a pattern similar to the central parameters, but the decrease was more stable after LASIK, and the tendency for the increase between the first postoperative days and the final visit was smaller compared to that of the parameters representing the central part of the image. This difference might be caused by additional factors such as polarisation effects from the transition zone in hyperopic eyes or from the border between the treatment zone and the intact cornea in myopic eyes, since the illuminating laser beam also passes through the paracentral cornea on its path to and from the retina in young subjects with relatively wide pupil.

The change in the astigmatism due to LASIK showed no correlation with the decrease of the RNFLT. Our finding that the central corneal thickness and the decrease of the central corneal thickness due to LASIK show no correlation with the changes of the polarimetric RNFLT is in accord with another study reporting no correlation between the central corneal thickness and the RNFLT in healthy eyes. ${ }^{35}$

In summary, our findings support the idea that the decrease of the polarimetric RNFLT following LASIK as measured with the GDx nerve fibre analyser represents only a virtual nerve fibre layer thinning in uncomplicated cases, and that it is caused by alterations of the polarisation properties of the laser treated cornea. This virtual thinning, however, is not stable during the healing process of the cornea. A clear tendency for 
the measurements to return to the preoperative baseline values was observed during the first 3 months of the postoperative period. This suggests that the short term investigations published to date on the apparent retinal nerve fibre layer thinning due to LASIK should be extended with studies including a longer follow up period, in order to define the typical course of the apparent thickness variation during the postoperative period, and in particular to determine the time period after which the disturbing effects can be considered to have stabilised, and the polarimetric thickness measurements therefore usable for diagnostic and follow up purposes.

\section{ACKNOWLEDGEMENT}

This work was supported by Hungarian national grant for medical research no ETT 293/2000.

\section{Authors' affiliations}

G Holló, Z Z Nagy, I Süveges, 1 st Department of Ophthalmology, Semmelweis University, Budapest, Hungary

P Vargha, Biometry Unit

The authors have no financial interest in any instrument or technique used in the study.

Correspondence to: Gábor Holló, MD, PhD, 1st Department of Ophthalmology, Semmelweis University, H-1083, Budapest, Tömö u 25-29, Hungary; hg@szem 1.sote.hu

Accepted for publication 8 February 2002

\section{REFERENCES}

1 Tion-Fo-Sang MJ, Lemij HG. The sensitivity and specificity of nerve fiber layer measurements in glaucoma as determined with scanning laser polarimetry. Am J Ophthalmol 1997;123:62-9

2 Holló G, Süveges I, Nagymihály A, et al. Scanning laser polarimetry of the retinal nerve fibre layer in primary open angle and capsular glaucoma. Br J Ophthalmol 1997;81.857-61.

3 Weinreb R N, Zangwill L, Berry C C, et al. Detection of glaucoma with scanning laser polarimetry. Arch Ophthalmol 1998;116:1583-9.

4 Yamada N, Chen P P, Mills R P, et al. Glaucoma screening using the scanning laser polarimeter. J Glaucoma 2000:9:254-61.

5 Colen TP, Tjon-Fo-Sang MH, Mulder PGH, et al. Reproducibility of measurements with the Nerve Fiber Analyzer (NFA/GDx). J Glaucoma 2000;9:363-70.

6 Choplin NT, Lundy DC. The sensitivity and specificity of scanning laser polarimetry in the detection of glaucoma in a clinical setting. Ophthalmology 2001;108:899-904

7 Poinoosawmy D, Tan JCH, Bunce C, et al. The ability of the GDx Nerve Fibre Analyser neural network to diagnose glaucoma. Graefes Arch Clin Exp Ophthalmol 2001;239:122-7.

8 Poinoosawmy D, Tan JCH, Bunce C, et al. Longitudinal nerve fibre layer thickness change in normal-pressure glaucoma. Graefes Arch Clin Exp Ophthalmol 2000;238:965-9

9 Holló G, Szabó A, Vargha P. Scanning laser polarimetry versus frequency doubling perimetry and conventional threshold perimetry: changes during a 12 month follow-up in preperimetric glaucoma. Acta Ophthalmol Scand 2001;79:403-7.

10 Khong CH, Waldock A, Spry PGD, et al. Longitudinal measurements with scanning laser polarimetry and perimetry in ocular hypertension and glaucoma. Invest Ophthalmol Vis Sci 2001;42:S15 (abstract No 86).
11 Weinreb RN, Dreher AW, Coleman A. Histopathologic validation of Fourier-ellipsometry measurements of retinal nerve fiber thickness. Arch Ophthalmol 1990;108:557-60.

12 Quigley HA. Neuronal death in glaucoma. Progr Retinal Eye Res 1998;18:39-57.

13 Osborne NN, Wood JPM, Chidlow G, et al. Ganglion cell death in glaucoma: what do we really know? Br J Ophthalmol 1999:83:980-6.

14 Kogure S, Chiba T, Kinoshita T, et al. Effects of artefacts on scanning laser polarimetry of retinal nerve fibre layer thickness measurement. $\mathrm{Br} J$ Ophthalmol 2000;84:1013-17.

15 Greenfield DS, Knighton RW, Huang X-R. Effect of corneal polarization axis on assessment of retinal nerve fiber layer thickness by scanning laser polarimetry. Am J Ophthalmol 2000;129:715-22.

16 Greenfield DS, Knighton RW. Stability of corneal polarization axis measurements for scanning laser polarimetry. Ophthalmology 2001;108:1065-9.

17 Mardelli PG, Piebenga LW, Whitacre MM, et al. The effect of excimer laser photorefractive keratectomy on intraocular pressure measurements using the Goldmann applanation tonometer. Ophthalmology 1997; 104:945-9.

18 Chatteriee A, Shah S, Bessant DA, et al. Reduction of intraocular pressure after excimer laser photorefractive keratectomy. Ophthalmology 1997; 104:355-9.

19 Rosa N Cennamo G, Breve MA, et al. Goldmann applanation tonometry after myopic photorefractive keratectomy. Acta Ophthalmol Scand 1998;76:550-4.

20 Ginemo JAS, Muñoz LA, Valenzuela LA, et al. Influence of refraction on tonometric readings after photorefractive keratectomy and laser assisted in situ keratomileusis. Cornea 2000:19:512-16.

21 Garzozi HJ, Chung HS, Lang $Y$, et al. Intraocular pressure and photorefractive keratectomy. Cornea 2001;20:33-6.

22 Holló G, Nagymihály A, Vargha P. Scanning laser polarimetry in corneal haze after excimer laser refractive surgery. J Glaucoma 1997;6:359-62.

23 Choplin NT, Schallhorn SC. The effect of excimer laser photorefractive keratectomy for myopia on nerve fiber layer thickness measurements as determined by scanning laser polarimetry. Ophthalmology 1999;106:1019-23

24 Gürses-Özden R, Pons ME, Barbieri C, et al. Scanning laser polarimetry measurements after laser-assisted in situ keratomileusis. Am J Ophthalmo 2000;129:461-4.

25 Tsai $Y$-Y, Lin J-M. Effect of laser-assisted in situ keratomileusis on the retinal nerve fiber layer. Retina 2000;20:342-5.

26 Gürses-Özden R, Liebmann JM, Schuffner D, et al. Retinal nerve fiber layer thickness remains unchanged following laser-assisted in situ keratomileusis. Am J Ophthalmol 2001;132:512-16.

27 Weiss HS, Rubinfeld RS, Anderschat JF. LASIK-associated visual loss in a glaucoma suspect. Arch Ophthalmol 2001;119:774-5.

28 Cameron BD, Saffra NA, Strominger MB. Laser in situ keratomileusis-induced optic neuropathy. Ophthalmology 2001;108:660-5.

29 Bushley DM, Parmley VC, Paglen P. Visual field defect associated with laser in situ keratomileusis. Am J Ophthalmol 2000;129:668-71.

30 Nagy ZZ, Fekete O, Süveges I. Photorefractive keratectomy for myopia with the Meditec MEL 70 G-scan flying spot excimer laser. J Refract Surg $2001 ; 17: 319-26$

31 Battat L, Macri A, Dursun D, et al. Effects of laser in situ keratomileusis on tear production, clearance, and the ocular surface. Ophthalmology 2001:108:1230-5.

32 Toda I, Asano-Kato N, Komai-Hori Y, et al. Dry eye after laser in situ keratomileusis. Am J Ophthalmol 2001;132:1-7.

33 Vesaluoma M, Pérez-Santonja J, Petroll WM, et al. Corneal stromal changes induced by myopic LASIK. Invest Ophthalmol Vis Sci 2000:41:369-76.

34 Pisella P-J, Auzerie O, Bokobza Y, et al. Evaluation of corneal stromal changes in vivo after laser in situ keratomileusis with confocal microscopy. Ophthalmology 2001; 108:1744-50.

35 lester M, Mermoud A. Retinal nerve fiber layer and physiological central corneal thickness. J Glaucoma 2001;10:158-62. 